families is hard to find. However, the proposition that antidepressants may have similar effects at all ages is inconsistent with our findings of quite limited, and perhaps inversely age-dependent, efficacy of antidepressants, as a class, as well as a lack of statistically significant differences between older and modern agents (especially of tricyclics $v$. serotonin reuptake inhibitors), and the powerful influence of study size on conclusions about 'significance' of separation of antidepressants from placebos. ${ }^{1}$

A timely and pressing question is whether antidepressant treatment alters suicidal risks. Depression and suicide are strongly associated, but prediction of suicidal behaviour, even in individuals with depression, is very difficult, and evidence concerning relationships of antidepressant treatment to suicidal behaviour, although consistent in randomised clinical trials, remains controversial. ${ }^{2,3}$ Whether or not youth suicide rates will consistently increase or decrease, remains to be seen, and to be sorted out from high international variation in yearly suicide rates and poor documentation of attempts. ${ }^{2}$

For now, it seems an inescapable conclusion that clinicians are left to their own clinical judgement about using antidepressants for young individuals diagnosed with major depressive disorder. Furthermore, disbelief that modern antidepressants show relatively modest effects compared with placebos and fail to separate statistically from older agents, ${ }^{1}$ paired with the repeated and the poorly documented assertion that some modern antidepressants work well in clinical practice, seems to avoid the issues. We considered various ways in which even randomised controlled trials may be misleading, including selection of atypical or mildly ill out-patients or use of inadequate doses of antidepressants, ${ }^{1}$ as well as current controversy about how to diagnose and quantify changes in affective disorders in children and adolescents. ${ }^{4}$ Nevertheless, it is difficult to simply dismiss and ignore the findings of the research that has been done to test the efficacy of antidepressants in juvenile depression. ${ }^{1}$

1 Tsapakis EM, Soldani F, Tondo L, Baldessarini RJ. Efficacy of antidepressants in juvenile depression: meta-analysis. Br J Psychiatry 2008; 193: 10-7.

2 Baldessarini RJ, Tondo L, Strombom I, Dominguez S, Fawcett J, Oquendo M, et al. Analysis of ecological studies of relationships between antidepressant utilization and suicidal risk. Harv Rev Psychiatry 2007: 15: 133-45.

3 Hammad TA, Laughren T, Racoosin J. Suicidality in pediatric patients treated with antidepressant drugs. Arch Gen Psychiatry 2006; 63: 332-3.

4 Henry C, Demotes-Mainard J. SSRIS, suicide and violent behavior: is there need for a better definition of the depressive state? Curr Drug Saf 2006; 1: 59-62.

\footnotetext{
Evangelia M. Tsapakis, Department of Psychological Medicine and MRC Social, Genetic and Developmental Psychiatry Centre, Institute of Psychiatry, King's College London, UK. Email: e.tsapakis@iop.kcl.ac.uk; Federico Soldani, Department of Epidemiology, Harvard School of Public Health, and Department of Psychiatry, Harvard Medical School and Psychopharmacology Program, McLean Division of Massachusetts General Hospital, Boston, Massachusetts, USA; Leonardo Tondo, ucio Bini, Mood Disorder Centre and Department of PSychology University of Lacio Bini, Mood Disorder Psychiatry, Harvard Medical School, Psychopharmacology Program and International Consortium for Bipolar Disorder Research, McLean Division of Massachusetts General Hospital, Boston, Massachusetts, USA

doi: 10.1192/bjp.194.2.189b
}

\section{Effects of an earthquake on suicide rates in Nantou, Taiwan}

The massive earthquake in Sichuan, China, that occurred on 12 May 2008 left 92000 dead or missing, almost 374000 injured, and millions homeless.

Rebuilding the communities is a huge task and much is to be learnt from communities with similar experiences. On 21 September 1999, Nantou County in Taiwan experienced an earthquake measuring 7.3 on the Richter scale. It caused more than 2000 deaths, 10000 injuries and 100000 collapsed buildings. ${ }^{1}$
After the earthquake, the number of suicides surged in Nantou. ${ }^{1,2,3}$ The general patterns of suicide in both regions are similar; ${ }^{4,5}$ what happened in Nantou after the earthquake should inform suicide prevention in Sichuan.

Table 1 shows the suicide rates in Nantou before and after 1999. The female suicide rate more than doubled immediately from 6.1 in 1998 to 14.2 in 1999 , whereas a very small increase was observed in males. However, the male suicide rate showed substantial increases in both 2000 and 2001, indicating a delayed effect. On the whole, the rate of increase in Nantou was higher than that in other parts of Taiwan (81\% v. 25\%).

\begin{tabular}{|c|c|c|c|c|c|c|}
\hline & \multicolumn{2}{|c|}{ Male } & \multicolumn{2}{|c|}{ Female } & \multicolumn{2}{|c|}{ Overall } \\
\hline & Nantou & Taiwan & Nantou & Taiwan & Nantou & Taiwan \\
\hline \multicolumn{7}{|c|}{ Suicide rate (per 100000 ) } \\
\hline 1998 & 18.6 & 12.8 & 6.1 & 6.9 & 12.6 & 9.9 \\
\hline 1999 & 19.0 & 13.7 & 14.2 & 6.8 & 16.7 & 10.3 \\
\hline 2000 & 23.7 & 14.4 & 13.1 & 7.6 & 18.7 & 11.1 \\
\hline 2001 & 33.6 & 16.6 & 11.2 & 8.0 & 22.9 & 12.4 \\
\hline \multicolumn{7}{|c|}{$\begin{array}{l}\text { Change when compared } \\
\text { with } 1998, \%\end{array}$} \\
\hline 1999 v. 1998 & 2.32 & 6.64 & 131.92 & -1.01 & 32.36 & 3.93 \\
\hline 2000 v. 1998 & 27.57 & 12.81 & 114.01 & 9.84 & 47.55 & 11.68 \\
\hline 2001 v. 1998 & 80.99 & 29.77 & 82.25 & 16.21 & 81.09 & 24.97 \\
\hline
\end{tabular}

The death of one's spouse may trigger suicidal thoughts, especially when compounded with the loss of the major income source. As men are more likely to be the 'bread winner' in rural areas, widows might suffer from a profound feeling of hopelessness immediately after a natural disaster. In the case of Sichuan, it is further aggravated by the loss of many children in the collapsed schools, many of them from one-child families (owing to the State's family policy). In contrast, unemployment carries major risk for male suicides; men are likely to be of high risk when the earthquake's impact on the local economy is fully manifested. This can explain the gender difference in the timing of heightened suicide risk in Nantou. It also suggests that the restoration efforts in Sichuan should devote resources to preventing suicide attempts among women in the short term, while devising strategies to prevent further causalities for male suicides before the local economy fully recovers.

\section{Acknowledgements}

The author would like to pay tribute to those who have worked tirelessly to save the survivors.

1 Han SN, Chen KT. Mortality of the 921 earthquake in Nantou and Taichung counties. Epidemiol Bull 2000; 1: 1-8.

2 Liaw YP, Wang PW, Huang CC, Chang CM, Lee WC. The suicide mortality rates between 1997-1998 and 2000-2001 in Nantou County of Taiwan following the earthquake of September 21 in 1999. J Forensic Sci 2008; 53: 199-202.

3 Chou YJ, Huang N, Lee CH, Tsai SL, Tsay JH, Chen LS. Suicides after the 1999 Taiwan earthquake. Int J Epidemiol 2003; 32: 1007-14.

4 Liu KY, Beautrais A, Caine E, Chan C, Chao A, Conwell Y, et al. Charcoal burning suicides in Hong Kong and urban Taiwan: an illustration of the impact of a novel suicide method on overall regional rates. $J$ Epidemiol Community Health 2007: 61: 248-53.

5 Yip $\mathrm{P}$, Liu $\mathrm{K}$, Song XM, Hu JP. Suicide rate in China during a decade of rapid social changes. Soc Psychiatr Psychiatr Epidemiol 2005; 40: 792-8.

Paul Yip, Social Work and Social Administration, Centre for Suicide Research and Prevention, The University of Hong Kong, Hong Kong. Email: sfpyip@hku.hk

doi: 10.1192/bjp.194.2.190 